\title{
Crítica marxiana ao enfrentamento da pobreza nos limites da razão ${ }^{1}$ política / Marxian critique to the attempt of coping with poverty within the limits of political reason
}

\section{Maria Fernanda Escurra²}

Resumo: Neste artigo explora-se um pequeno texto escrito por Marx em que ele analisa o pauperismo clássico inglês do século XIX e concentra sua crítica nas formas de consciência da burguesia que orientavam o gerenciamento desse fenômeno social nos limites da razão política. Por isso, são feitas breves consideraçôes sobre os limites da emancipação política em oposição à emancipação humana. Entendido como problema político, administrativo, de beneficência, ou mesmo atribuído a deficiências individuais do próprio pobre, o fenômeno da pobreza é inteiramente compatível com a "crítica positiva", tipo de crítica circunscrita ao mundo tal como ele existe. Desde o tempo em que Marx escreveu seu artigo até os dias de hoje, conclui-se que pouco mudou na forma como a pobreza é compreendida pela teoria social corrente. Esta interpretação hegemônica não é capaz de apreender o fenômeno, a sua gênese e persistência, pelo simples fato que não leva em conta a especificidade da forma de organização social capitalista. Daí a necessidade de restaurar a teoria social de Marx como uma "crítica negativa" desta forma de vida social.

Palavras-chave: Marx; crítica; gerenciamento; pobreza.

1 Artigo elaborado tendo como base texto extraído da Tese de doutorado intitulada Pobreza no capitalismo: elementos para a análise crítica com base na teoria valor-trabalho de Marx, apresentada em 2015 ao Programa de Pós-Graduação em Serviço Social da Universidade do Estado do Rio de Janeiro, contando com bolsa da Fundação de Amparo à Pesquisa do Estado do Rio de Janeiro (Faperj).

2 Assistente Social, consultora da Faculdade de Engenharia da Universidade do Estado do Rio de Janeiro (Uerj). Mestrado em Serviço Social pela Universidade Federal do Rio de Janeiro. Doutora em Serviço Social pela Uerj. 


\begin{abstract}
This article explores a small text written by Marx in which he analyzes the classic pauperism of the nineteenth century - English pauperism - and focuses his criticism on the forms of conscience of the bourgeoisie that underlined management of this social phenomenon within the limits of the political reason. For this reason, brief considerations are made about the limits of political emancipation in opposition to human emancipation. Understood as a political, administrative, charitable problem, or even ascribed to individual deficiencies of the poor itself, the phenomenon of poverty is entirely compatible with the "positive criticism", kind of critique circumscribed to the world as it exists. From the time of Marx's article up to the present day, it is concluded that little has changed in the way poverty is understood by the mainstream social theory. This hegemonic interpretation is not able to apprehend the phenomenon, its genesis and persistence, for the simple fact that it does not take into account the specificity of the capitalist form of social organization. Hence the necessity to restore the Marxian social theory as a "negative critique" of this social form of life.
\end{abstract}

Keywords: Marx; critical; management; poverty.

$\mathrm{M}$ arx, em um pequeno texto, escrito em $1844,{ }^{3}$ intitulado Notas marginais críticas ao artigo "O Rei da Prússia e a Reforma Social. Por um Prussiano", analisa o pauperismo clássico inglês do século XIX e concentra sua crítica às formas de consciência da burguesia que orientavam o gerenciamento político-administrativo desse fenômeno social nos limites da razão ou visão política. Entendido como problema político, administrativo, de beneficência, ou mesmo atribuído a deficiências individuais do próprio pobre, o fenômeno da pobreza é inteiramente compatível com a "crítica positiva", tipo de crítica circunscrita ao mundo tal como ele existe. Nesse sentido, inicialmente é assinalada a existência de dois tipos de crítica, a "positiva" e a "negativa" e, na sequência, após a apresentação da análise marxiana sobre o pauperismo

3 Medeiros (2013, p. 160) ressalta que esse curto texto de 1844, em que Marx desenvolve uma crítica ao prussiano social-democrata A. Ruge, é considerado por muitos uma inflexão no pensamento marxiano de uma postura democrata radical para a admissáo explícita do comunismo. 
clássico inglês de sua época, são feitas breves considerações sobre os limites da emancipação política em oposição à emancipação humana.

\section{Crítica positiva e crítica negativa}

A existência de dois tipos de crítica, a "crítica positiva" e a "crítica negativa", é destacada por Duayer (2011, p. 98) que define "positiva" como aquela que considera o mundo como um dado insuperável, inalterável, de modo que a compreensão, descrição e as práticas estimuladas por tal crítica sempre se circunscrevem a este mundo imediato, anistórico. Consequentemente, a crítica positiva interdita, por princípio, "toda prática que transcende os limites da reprodução do existente, seja em conformidade com uma concepção anistórica da sociedade, seja em razão de uma concepção da história como absoluta contingência” (DUAYER, p. 99). Tal concepção, esclarece o autor, não significa indiferença às infâmias deste mundo. Todavia, se as misérias sociais são próprias da forma social, neste caso, capitalista, uma ciência social, sendo positiva, evidentemente não tem como investigar as verdadeiras causas das misérias sociais, restringindo-se, por isso, a estudar formas de atenuar e gerenciar os efeitos dos "sofrimentos cotidianos" sempre nos limites deste mundo. De maneira similar, Postone (2014, p. 111) define, em poucas palavras, a crítica positiva como a que "critica o que é com base no que também é e, portanto, não aponta realmente para além da totalidade existente".

Por contraste com tal modalidade de crítica, a teoria social marxiana é "crítica negativa" da sociedade do capital. Trata-se da "crítica das formas correntes de figurar o mundo, das descriçóes correntes do mundo, compatíveis com e necessárias para um mundo que parece se reproduzir sempre da mesma forma”. Consequentemente, em oposiçáo à crítica positiva, a crítica negativa figura "o mundo social como mundo histórico, portanto, mutável [...] [abrindo] espaço para práticas sociais compatíveis com a historicidade do mundo" (DUAYER, 2011, p. 99). 


\section{Pobreza como problema político, administrativo ou filantrópico}

A crítica feita por Marx, no artigo de 1844, mostra que as análises e as propostas de tratamento da pobreza nos limites da "razão política" se concretizam em reformas político-administrativas implementadas pelo Estado. Assim, a pobreza, no limite da razão ou visão política, é atribuída a problemas administrativos, políticos, de beneficência ou mesmo a problemas ou deficiências individuais do próprio pobre. Em resposta à pergunta se o Estado pode proceder de outra forma, Marx é categórico ao afirmar: "o Estado jamais encontrará no 'Estado e na organização da sociedade', [...] a causa das mazelas sociais" (s/d, p. 6).

$\mathrm{Na}$ análise, o autor examina o "caráter limitado do ponto de vista político" e demonstra que, com esse ponto de vista, é impossível que o Estado elimine o pauperismo e as mazelas sociais, pois desconsidera que sua própria existência e a do pauperismo são resultados de sociedades divididas em classes sociais, com interesses privados antagônicos aos interesses coletivos.

A grande descoberta de Marx e Engels, no campo da teoria política, ressalta Coutinho, foi a afirmação do caráter de classe de todo Estado e, ademais, a identificação tendencial do Estado com o conjunto de seus aparelhos repressivos:

[a] gênese do Estado reside na divisão da sociedade em classes, razão por que ele só existe quando e enquanto existir essa divisão [...] e a função do Estado é precisamente a de conservar e reproduzir tal divisão, garantindo assim que os interesses comuns de uma classe se imponham como o interesse geral da sociedade (COUTINHO, 1992, p. 74, grifos do autor). ${ }^{4}$

4 Ver a análise de Eagleton (2012, Capítulo IX, p. 164-175) sobre a posiçâo de Marx em relaçấo ao Estado. O autor assinala que "Marx encara o Estado com um realismo frio [...] Aos Estados não compete deflagrar revoluçóes contra a propriedade. Eles existem, entre outras coisas, para defender a ordem social corrente contra aqueles que buscam transformá-la. Se essa ordem é inerentemente injusta, nesse ponto o Estado também é injusto. [...] Não há nada de sobriamente conspiratório na ideia de que o Estado é tendencioso" (MARX, p. 165). No entanto, o autor observa que "[i]sso não sugere a possibilidade de descartar a polícia, os tribunais, as prisóes nem mesmo os esquadróes para militares. Os últimos, por exemplo, podem se revelar necessários se um bando de terroristas munidos de 
Nessa perspectiva, Marx - contrapondo-se à falsa compreensão do "prussiano" (Ruge), que explica a miséria dos trabalhadores alemães a partir da peculiaridade de um "país apolítico" - afirma que a análise da Inglaterra, país por excelência político e da miséria universal dos trabalhadores, é a maneira mais segura para compreender a relaçấo de um país político com o pauperismo e examinar se não eram igualmente falsas as concepçóes inglesas sobre a miséria.

A burguesia inglesa admite o pauperismo como "culpa da política”, só que nenhum dos partidos encontra a causa na política em geral, mas na política do partido oposto "uma reforma da sociedade é algo com que ambos os partidos sequer sonham" (MARX, s/d, p. 3). Marx afirma que o perigo do pauperismo e os meios para repará-lo são compreendidos pela burguesia inglesa "de forma infantil e tola". A burguesia inglesa e sua imprensa compreendem a epidemia nacional do pauperismo com "imensa irreflexão".

Já a economia política inglesa, ${ }^{5}$ forma de consciência científica, diz ele, é a expressão mais categórica da compreensão inglesa do pauperismo: Mac Culloch, por exemplo, naturaliza a miséria e aprecia a "incansável sabedoria dos homens" para "superar obstáculos" e "avançar passo a passo no caminho da superação da pobreza”; e o Dr. Kay reduz o problema ao "descaso com a educação" (MARX, p. 3-4). Compartilhando essa mesma opinião, o ingênuo "prussiano" [Ruge],

armas químicas ou nucleares estiver à solta. [...] Nem toda violência estatal tem como finalidade proteger o status quo. O próprio Marx faz uma distinção no terceiro volume de $O$ capital entre as funçóes do Estado especificamente relativas à classe e as neutras nesse sentido. Policiais que evitam que canalhas racistas surrem uma jovem asiática até a morte não estáo agindo como representantes do capitalismo. [...] Não existem indícios de que Marx teria rejeitado qualquer dessas afirmaçóes. Ele acreditava que o Estado pudesse ser uma força poderosa em prol do bem. Por esse motivo, defendeu com veemência uma legislação para melhorar as condiçóes sociais na Inglaterra vitoriana. [...] O que Marx rejeitava era o mito sentimental do Estado como uma fonte de harmonia, pacificamente unindo diferentes grupos e classes. Buscava, sim, [o Estado] manter a sociedade unida, mas basicamente, para satisfazer os interesses da classe governante. Por baixo de sua aparente imparcialidade residia uma forte parcialidade". (EAGLETON, 2012, p. 166-167).

5 Em $O$ capital, Marx apresenta diversas formas como os economistas políticos entendem a miséria e diferentes propostas que eles sugerem para seu enfrentamento. (Cf. 1994, L. 1, v. 2, p. 749-751). 
sem entender que o rei da Prússia seguiu o único caminho que um chefe de Estado poderia seguir, pergunta "por que não ordena imediatamente a educação de todas as crianças desamparadas” (MARX, p. 5, grifos do autor) como medida para acabar com o pauperismo?

A legislação inglesa de beneficência contra o pauperismo por via administrativa durou dois séculos, observa Marx, e o aumento terrível do pauperismo é explicado como uma "deficiência administrativa". Para o parlamento inglês, a principal causa da situação crítica do pauperismo no país estaria na "própria Lei dos Pobres" combinada com a "culpabilização dos trabalhadores". (MARX, s/d, p. 5).

A Inglaterra, primeiramente, tentou "erradicar o pauperismo" por meio da "beneficência" e de "medidas administrativas". O pauperismo compreendido como uma "lei natural e eterna", conforme a teoria malthusiana, seria resultado do aumento incessante da população em relação aos meios de subsistência e não uma consequência das relaçóes sociais de produção. A Inglaterra:

[...] não viu, então, o progressivo aumento do pauperismo como a necessária consequência da indústria moderna, mas sim como consequência da taxa dos pobres inglesa. Ela concebeu a miséria universal unicamente como uma particularidade da legislaçáo inglesa. O que era anteriormente atribuído à falta de caridade passou a ser atribuído ao excesso de caridade. Finalmente, a miséria foi considerada culpa dos miseráveis e, deste modo, neles infligida. (MARX, s/d, p. 5, grifos do autor).

6 Marx (2008, p. 147-148) destaca que a "escola humanitária" assume o lado mau das relaçóes de produção atuais e procura, por desencargo de consciência, dissimular ao menos um pouco os verdadeiros contrastes. Desse modo, aconselha os trabalhadores a serem sóbrios, a terem poucos filhos; ao passo que recomenda aos burgueses pôr na produção uma paixão controlada. $\mathrm{O}$ autor observa que toda a teoria desta escola assenta-se em infinitas distinçóes entre "a teoria e a prática", "o lado bom e o lado ruim". Por sua vez, considera que a "escola filantrópica" é a "escola humanitária aperfeiçoada". Esta escola nega os antagonismos e procura transformar todos os homens em burgueses, tornando, assim, esta teoria a realidade idealizada que mantém as categorias que expressam as relaçóes burguesas, mas sem o antagonismo que as constitui. 
O exame do caso francês, mostra Marx, confirma que a burguesia desse país também foi incapaz de eliminar a miséria por meio de medidas administrativas. Ele recorda que Napoleão ordenou ao seu Ministro do Interior colocar auditores, prefeitos e engenheiros em ação para "eliminar a mendicância no prazo de um mês", após ter perdido a paciência diante da falta de resposta das autoridades à sua ordem de erradicar a mendicância em toda a França. Tudo foi cumprido em poucos meses, e a "imagem repugnante das enfermidades e da vergonhosa miséria" foi eliminada mediante a promulgaçáo de uma lei, em julho de 1808, que reprimia a mendicância, encarcerando os pobres (MARX, s/d, p. 5-6). ${ }^{7}$

Voltando ao caso inglês, Marx identifica a existência de uma “administração do pauperismo extensa e ramificada" que, longe de qualquer originalidade, não tem como finalidade a erradicação do fenômeno, mas o seu "disciplinamento" e "perpetuação" por meios "positivos": "ela contenta-se em cavar-lhe um túmulo, com clemência policial, toda vez que ele transborda para a superfície do país oficial" (MARX, s/d, p. 5). Mais ainda, novamente com uma análise que ultrapassa as fronteiras inglesas, afirma: "onde quer que os Estados tenham se ocupado do pauperismo, eles não foram além de medidas administrativas e filantrópicas ou desceram abaixo da administração e da beneficência”. (MARX, p. 6, grifos do autor).

Situação que Marx explica observando que o Estado e a organização da sociedade, do ponto de vista político, não são duas coisas diferentes: "[o] Estado é a organização da sociedade" (MARX, p. 7). O Estado compreende a existência de mazelas sociais como consequência de leis naturais, da vida privada ou as explica pela má vontade dos pobres. Em razáo disso, todos os Estados procuram a causa do pauperismo em "falhas acidentais ou intencionais da administração" e, sendo a administração a atividade organizadora do Estado, a solução para as

7 Para ilustrar a atualidade destas formas de enfrentamento da pobreza ver Wacquant (2002). Nesta obra, entre outras, o autor analisa, tomando o modelo norte -americano como caso exemplar, o processo contemporâneo de desenvolvimento do capitalismo e a passagem do "Estado de Bem-Estar Social" ao "Estado Penal", examinando o sistema penal como instrumento privilegiado de "regulação e criminalização da miséria", de "armazenamento dos refugos do mercado", de controle das novas "classes perigosas" e a prisão que passa a substituir o gueto. 
mazelas é procurada no "ajuste das medidas da administração". Em síntese, o Estado procura a existência de mazelas sociais:

[...] em leis naturais [...] ou na vida privada que é independente dele, ou na disfuncionalidade da administração, que dele depende. [...] O pauperismo, por outro lado, é explicado pela má vontade dos pobres [...] Finalmente, todos os Estados procuram a causa em falhas acidentais ou intencionais da administração e, portanto, no ajuste das medidas da administração a solução para as mazelas. Por quê? Precisamente porque a $a d m i-$ nistração é a atividade organizadora do Estado. (MARX, s/d, p. 7, grifos do autor).

Em sua análise, Marx defende que a natureza do Estado moderno está fundada na contradição entre os "interesses gerais" e os "interesses particulares”. A própria existência do Estado depende da existência de antagonismos sociais, da divisão da sociedade em classes sociais com interesses opostos. Ele ressalta, ainda, que se o Estado quisesse eliminar a "impotência" de sua administração seria necessário eliminar a atual vida privada e a própria existência do Estado. Por esse motivo, sua administração deve restringir-se a uma atividade formal sem capacidade, diante do caráter limitado da razão política, de eliminar as mazelas sociais.

O caráter limitado da razão política relaciona-se ao fato de que quanto mais político é o Estado menos disposto ele está de procurar a causa das mazelas sociais na "atual organização da sociedade social". Marx demonstra, deste modo, ao "prussiano" que as açóes implementadas na Inglaterra para enfrentar o pauperismo não se diferenciam das medidas propostas pelo governo prussiano, confirmando, assim, "quão incapaz é o entendimento político de descobrir a fonte da miséria social" (MARX, s/d, p. 11, grifos do autor). Em outros termos, "o entendimento político é precisamente entendimento político porque pensa no interior dos limites da política" (MARX, p. 7, grifos do autor). Nas palavras do autor:

[a] contradição entre a finalidade e a boa vontade da administração, de um lado, e os seus meios e capacidade, do outro, o Estado não pode eliminar sem eliminar a si mesmo, já que se baseia nesta contradição. [...] diante das consequências que se originam da natureza antissocial desta vida burguesa, desta 
propriedade privada, deste comércio, desta indústria, desta pilhagem recíproca dos diferentes círculos burgueses, diante destas consequências, a impotência é a lei natural da administração. Pois esta dilaceração, esta infâmia, esta escravidão da sociedade burguesa é o fundamento natural onde repousa o Estado moderno. [...] não pode (o Estado) acreditar na impotência interna de sua administração, isto é, de si mesmo. Ele pode reconhecer somente suas deficiências formais, casuais, e tentar remediá-las. Se estas modificaçôes são infrutíferas, então o mal social é natural, independente das imperfeiçôes dos homens. (MARX, p. 7, grifos do autor).

No entanto, é necessário esclarecer que o entendimento da incapacidade do Estado em eliminar o pauperismo e as mazelas sociais não significa desconhecer a importância de conquistas das lutas políticas. Inclusive, conquistas importantes, resultado de lutas da classe trabalhadora, foram contemporâneas do próprio Marx e, posteriormente, com o desenvolvimento do próprio capitalismo expressam a necessidade do Estado - em contraposição à noção de Estado restrito, coercitivo, enquanto "comitê executivo da classe dominante" - de garantir direitos sociais e políticas para atender demandas concretas que resultam de lutas da classe trabalhadora. ${ }^{8}$ De fato, a tarefa do Estado não se

8 Cf. Coutinho (1987, principalmente, p. 15-19 e 61-74; 1992, Capítulo 5: Teoria Ampliada do Estado, p. 73-88). O autor faz referência à necessidade de superação dialética da "concepçâo restrita" de Estado e à ampliação do conceito de Estado como resultado do próprio desenvolvimento do modo de produção e da formação econômico-social capitalista. Ele analisa o modo como Gramsci "amplia" a teoria marxista "clássica" de Estado com o conceito de "sociedade civil". Desse modo, em contraposição à concepção de Estado "restrita" de Marx como "sociedade política", a noção gramsciana expressa uma nova determinação do Estado que passa a ser considerado "como síntese da sociedade política e da sociedade civil, de Estado-coerção e de aparelhos privados de hegemonia" (COUTINHO, 1992, p. 81). Coutinho explica que "[e]nquanto a sociedade política tem seus portadores materiais nos aparelhos repressivos de Estado (controlados pelas burocracias executiva e policial-militar), os portadores materiais da sociedade civil são o que Gramsci chama de 'aparelhos privados de hegemonia', ou seja, organismos sociais coletivos voluntários e relativamente autônomos em face da sociedade política. [...] a necessidade de conquistar o consenso ativo e organizado como base para a dominação - uma necessidade gerada pela ampliação da socialização da política - criou e/ou renovou determinadas objetivaçóes ou instituiçóes sociais, que passaram a funcionar como portadores materiais específicos (com estruturas e legalidades próprias) das relaçóes sociais de hegemonia”. (Ibid., p. 77-78). 
limita a servir aos interesses imediatos da classe dominante, pois precisa também atuar para garantir a coesão social.

O próprio Marx apoiava e considerava necessárias e progressistas, apesar de intrínsecas à sociedade capitalista, certas reformas políticas relacionadas, por exemplo, à diminuiçâo da jornada de trabalho e à legislação fabril. ${ }^{9}$ Em suas palavras, "[e]ntre direitos iguais e opostos decide a força. Assim, a regulamentação da jornada de trabalho se apresenta, na história da produção capitalista, como luta pela limitação da jornada de trabalho, um embate que se trava entre a classe capitalista e a classe trabalhadora" (1994, L. I, V. 1, p. 265). Nesse particular, Postone (2014, p. 53-54) salienta que, em conformidade com Marx, as "manifestações de luta de classes entre os representantes do capital e os trabalhadores em torno de questóes associadas ao tempo de trabalho ou da relação entre salários e lucros, por exemplo, são estruturalmente intrínsecas ao capitalismo e, portanto, um importante elemento constitutivo do sistema”, fato que, naturalmente, não desqualifica tais lutas nem sua necessidade, mas apenas chama a atenção para seus limites. ${ }^{10}$

\section{Os limites da emancipaçáo política}

Para Marx, "[a] emancipação política é, sem dúvida, um grande progresso; ela não é, decerto, a última forma da emancipação humana, em geral, mas é a última forma da emancipação política no interior da ordem mundial até aqui". (MARX, 2009, p. 52, grifos do autor). A crítica desenvolvida por Marx aos "limites da emancipação política" fundamenta a necessidade de sua superação pela "emancipação humana"; a emancipação política é um "meio da emancipação humana" e "não o seu fim". Em seus termos, "[o] limite da emancipação política

9 Cf. Marx (1994, L 1, v. 1, p. 315-345 e 550-575).

10 Sob essa ótica, Marx escreve: “[p]ara proteger-se contra 'a serpe de seus tormentos' têm os trabalhadores de se unir e como classe compelir a que se promulgue uma lei que seja uma barreira social intransponível capaz de impedi-los definitivamente de venderem a si mesmos e sua descendência ao capital, mediante livre acordo que os condena à morte e à escravatura. $\mathrm{O}$ pomposo catálogo de direitos inalienáveis do homem será assim substituído pela modesta Magna Carta que limita legalmente a jornada de trabalho e estabelece claramente, por fim, 'quando termina o tempo que o trabalhador vende e quando começa o tempo que lhe pertence'. Que transformação". (1994, L. I, v. 1, p. 345). 
aparece logo no fato de que o Estado pode libertar-se de uma barreira sem que o homem esteja realmente livre dela, [no fato de] que o Estado pode ser um Estado livre sem que o homem seja um homem livre". (MARX, 2009, p. 48, grifos do autor).

A diferença entre "emancipação política" e "emancipação humana” é definida com precisão por Marx: a primeira é a emancipação funcional à ordem do capital, representa a realização histórica da sociabilidade regida pela propriedade privada burguesa. $\mathrm{O}$ grande progresso da emancipação política foi a dissolução da velha sociedade feudal, a eliminação dos privilégios da nobreza, mas garantiu, enquanto direito humano da liberdade, o direito humano à propriedade privada, assim como direitos e conquistas dos trabalhadores no interior da própria sociedade capitalista. $\mathrm{O}$ direito à propriedade privada é direito do interesse próprio, o direito de desfrutar de seu patrimônio, é o interesse pessoal, individual, sem atender aos demais homens, o que torna a liberdade individual um fundamento da sociedade burguesa (MARX, 2009, p. 64). Nessa mesma linha de argumento, segundo Marx, a segurança é o conceito supremo da sociedade burguesa, o conceito de polícia, utilizado para a conservação dos direitos de cada um dos membros da sociedade e da sua propriedade (MARX, 2009, p. 65). Em oposição à emancipação política, na perspectiva do autor, a emancipação humana se processa ao superar a sociabilidade regida pela propriedade privada burguesa e seu modo específico de produção e representa a mais completa e radical superação do mundo da emancipação política.

Emancipação política e emancipação humana são categorias marxianas precisas e a única relação possível entre ambas é a de negação histórica. Neste sentido, Marx é categórico ao afirmar: "[n]ão basta de modo algum investigar quem deve emancipar, quem deve ser emancipado. A crítica tinha uma terceira coisa a fazer. Tinha de perguntar: de que espécie de emancipação se trata? Que condições estão fundadas na essência da emancipação exigida?" (MARX, 2009, p. 44, grifos do autor). A emancipação humana, desse modo, representa uma transformação radical da sociedade que necessariamente envolve um ato político, mas que deve desaparecer com a sociedade emancipada. A revoluçấo em geral, a destruição do poder existente e a dissolução das antigas relaçóes: 
[...] é um ato político. Sem revolução o socialismo é irrealizável. Ele necessita deste ato político tanto quanto necessita da destruição e da dissolução. Quando, no entanto, tem início a sua atividade organizadora, quando se torna aparente o seu ser em si, o seu espírito, o socialismo desfaz-se de seu envoltório político. (MARX, s/d, p. 12).

No entanto, para enfatizar a atualidade e a grandeza do significado que Marx atribuía à emancipação humana, com o intuito de evitar incorrer na repetiçáo de formulaçóes que parecem meros enunciados abstratos, talvez seja oportuno recorrer à afirmação de Jappe (2013, p. 27) sobre a inexistência de uma teleologia que conduziria ao comunismo ou à emancipação; o certo é que a emancipação náo pode ser o simples resultado do desenvolvimento ou perpetuação do capitalismo, mudando apenas os gestores ou "libertando" as forças que ele mesmo teria criado: "[n]âo há como escapar dos constrangimentos estruturais do sistema democratizando o acesso a suas funções." (JAPPE, 2013, p. 30). Soma-se a isso a observação do autor de que, na atualidade, o que se apresenta como crítica do capitalismo é a grande parte do problema (e não parte da solução). Consistem em reaçôes à crise que ele denomina de "populismo" e que, na realidade, não criticam verdadeiramente as bases da produção capitalista, mas se limitam a procurar bodes expiatórios e, em consequência, a propor reformas. ${ }^{11}$ Assim como Jappe, há diferentes análises de marxistas contemporâneos que chamam a atenção para a necessidade da crítica à incapacidade do socialismo real produzir uma emancipação. ${ }^{12}$

11 Em sua opinião, “[a] emancipação não pode ser outra coisa senão a libertação em relação àquilo que impede a autonomia num nível mais profundo e mais geral. Essa emancipação só pode dizer respeito ao sistema capitalista e tecnológico em seu conjunto, sem privilegiar um desses dois aspectos [...] nada de simples 'apropriaçâo' da tecnologia industrial por parte de uma sociedade com pretensöes 'náo capitalistas', nada de sair da tecnologia, ou de seus excessos, sem demolir a valorização do valor, o trabalho abstrato e o capital. É preciso centrar fogo no fetichismo, enquanto sistema já pronto e acabado em que nenhuma decisão, pequena ou grande, é mais possivel". (JAPPE, 2013, p. 30-31, grifos nossos).

12 Para uma crítica do assim denominado "socialismo realmente existente" ver: Postone. (2014, p. 17-59). 


\section{Consideraçóes finais}

A análise feita por Marx sobre as formas de entendimento e enfrentamento do pauperismo clássico inglês, no século XIX, evidencia sua inegável atualidade e os limites da razão ou visão política. Entendido como problema político, administrativo, de beneficência, ou mesmo atribuído a deficiências individuais do próprio pobre, o fenômeno da pobreza é inteiramente compatível com a "crítica positiva", tipo de crítica circunscrita ao mundo tal como ele existe. Além disso, se pensada a pobreza nos dias de hoje, essa análise mostra: a falta de originalidade dos fundamentos teóricos das análises correntes do fenômeno da pobreza e suas propostas; a reatualização de antigas formas de análise; e a ilusão da possibilidade de superação do fenômeno no limite da própria forma de organização social considerada natural e eterna. Portanto, parece possível afirmar que há uma linha de continuidade nas formas de consciência teóricas e políticas da burguesia para o entendimento e tratamento da pobreza desde o século XIX até os dias atuais. De fato, independentemente de diferentes roupagens, persiste imperturbada:

[...] a mesma concepção naturalizada da sociedade do capital. Se com isso é incapaz de descobrir as verdadeiras causas dos problemas com que se defronta e sendo obrigada por dever de ofício a instrumentalizar 'soluções' que jamais solucionam, a consciência burguesa tampouco se molesta. Dispóe de um manancial de soluçôes, todas sempre implausíveis. Atividade que, admita-se, confere dinamismo à administraçấo governamental pela permanente substituição de antigos planos, cujos defeitos insanáveis calhou-se descobrir, por novos planos elaborados com os últimos recursos. (DUAYER; MEDEIROS, 2003, p. 258).

A leitura hegemônica da pobreza na época de Marx, assim como na atualidade, é incapaz de apreender o fenômeno, a sua gênese e persistência, pelo simples fato que desconsidera a especificidade da forma de organização capitalista. Com isso, a necessidade de restaurar a teoria social marxiana como "crítica negativa" desta forma de organização social. 
Submetido em 01 de dezembro de 2015 e aceito para publicação em 30 de março de 2016.

\section{Referências}

COUTINHO, C. N. Dualidade de poderes: introdução à teoria marxista de Estado e revolução. São Paulo: Brasilense, 1987.

Gramsci: um estudo sobre seu pensamento político. 2. ed., Rio de Janeiro: Campus, 1992.

DUAYER, M. Mercadoria e trabalho estranhado: Marx e a crítica do trabalho no capitalismo. Margem Esquerda. Ensaios marxistas, n. 17, nov./2011. São Paulo: Boitempo, p. 88-99.

DUAYER, M.; MEDEIROS, J. L. Miséria brasileira e macrofilantropia. Psicografando Marx. Economia Contemporânea, v. 7 (2), 2003, p. 237-262.

EAGLETON, T. Marx estava certo. Rio de Janeiro: Nova Fronteira, 2012.

JAPPE, A. Crédito à morte. A decomposição do capitalismo e suas críticas. Sáo Paulo: Hedra, 2013.

MARX, K. O capital. Crítica da Economia Política. 12. ed. livro 1, vs I e II, Rio de Janeiro: Bertrand Brasil, 1994.

Miséria da Filosofia. 2. ed. São Paulo: Martin Claret, 2008. . Para a questáo judaica. São Paulo: Expressão Popular, 2009.

- Notas marginais críticas ao artigo "O Rei da Prússia e a Reforma

Social. Por um Prussiano.” Jornal Vorwärts, n. 63, 07/08/1844. Trad.: Medeiros, J. L. s/d.

MEDEIROS, J. L. A economia diante do horror econômico: uma crítica ontológica dos surtos de altruísmo da ciência econômica. Niterói: UFF, 2013.

POSTONE, M. Tempo, trabalho e dominação social. São Paulo: Boitempo, 2014.

WACQUANT, L. Punir os pobres. A nova gestão da miséria nos Estados Unidos. Rio de Janeiro: Revan, 2002. 